SPECIAL ISSUE: ARTICLE

Lab and Field Experiments

\title{
Sustainability of renewable energy investment motivations during a feed-in-tariff scheme transition: evidence from a laboratory experiment
}

\author{
Jun Maekawa ${ }^{1} \cdot$ Koji Shimada $^{2} \cdot$ Ai Takeuchi $^{2}$
}

Received: 13 May 2021 / Revised: 5 August 2021 / Accepted: 11 August 2021 /

Published online: 20 August 2021

(C) The Author(s) 2021

\begin{abstract}
This study analyzes the effects of a feed-in-tariff (FIT) scheme's transition on renewable energy investments. We model an individual's investment decisions as a public goods game where the FIT scheme's purchasing price acts as a subsidy that lowers the individual's investment cost. Using a laboratory experiment, we study the effects of a decreasing purchasing price by comparing it to a counterfactual situation where the FIT scheme is not introduced. Although a high purchasing price induces higher investments, this external incentive seems to crowd out an individual's intrinsic motivation: when the purchasing price decreases to zero, an individual's investments are lower than they are in the counterfactual situation. Considering the possibility that motivation crowding out has occurred during the FIT phase-out process, it is important to introduce a new policy instrument without a break to stimulate renewable energy investments.
\end{abstract}

Keywords Feed-in-tariff scheme $\cdot$ Renewable energy $\cdot$ Public goods game Laboratory experiment $\cdot$ Motivation crowding out

Jun Maekawa

jmaekawa@fc.ritsumei.ac.jp

Koji Shimada

shimada@ec.ritsumei.ac.jp

Ai Takeuchi

ai-tak@fc.ritsumei.ac.jp

1 Ritsumeikan Global Innovation Research Organization, Ritsumeikan University, 1-1-1

Noji-higashi, Kusatsu-shi, Shiga 525-8577, Japan

2 College of Economics, Ritsumeikan University, 1-1-1 Noji-higashi, Kusatsu-shi,

Shiga 525-8577, Japan 


\section{Introduction}

The proliferation of renewable energy, such as solar, hydro, wind, and geothermal, is essential for building a sustainable society. Renewable energy has various advantages that make it a key building block of a sustainable society; these energy sources have almost zero resource costs and low environmental impact. Owing to its high importance, the spread of renewable energy is specified as one of the 14 sustainable development goals (SDG). However, owing to the high variability of supply volume and high initial installation cost, providing renewable energy through markets tends to be insufficient. Thus, various comprehensive policies are necessary for promoting the growth of renewable energy and achieving corresponding policy goals. One such policy framework, feed-in-tariff (FIT), is expected to have a particularly high impact on the diffusion of renewable energy.

The FIT scheme is a system in which power companies purchase renewable energy at higher prices as compared to the usual electric power contract price. This scheme serves as a Pigouvian subsidy to solve the under-provision of goods with positive externalities. For example, renewable energy's positive effects on the environment can be considered as a positive externality. However, its investment tends to be below the socially optimal level without policy support. Theoretically, the FIT scheme's purchasing price can be used to internalize the positive externalities of renewable energy and encourage further investment.

The FIT system has become a major instrument to encourage renewable energy investment worldwide since the 2000s. To achieve the greenhouse gas reduction targets based on the Kyoto Protocol and the Paris Agreement, several countries have set energy (or electricity) generation targets for promoting renewable energy by 2030 . In Japan, this target is $22-24 \%$ of the total energy generation, and it is approximately $40 \%$ in European Union (EU) countries such as Germany and France. FIT schemes have been adopted in these countries as a policy to achieve these targets.

Many countries started with a high FIT purchasing price (or increased it to a high level). However, this price has decreased over the last decade. Figure 1 shows the change in FIT purchasing price for solar energy in EU countries and Japan. In these countries, prices have been reduced or made zero because of various reasons.

In some countries, owing to the FIT scheme, renewable energy investments increased. Consequently, initial installation costs decreased due to economies of scale and technological progress. To curb excessive price hikes of renewable energy power generation companies, the FIT purchasing prices in such countries were reduced. In Germany, for example, FIT was introduced in 2000 by the Renewable Energy Sources Act (EEG Act). Germany's renewable energy ratio increased from approximately $6 \%$ when the FIT scheme was introduced to $40 \%$ in 2018. With the spread of renewable energy, the FIT scheme's role declined, and policy began shifting toward engendering competition in the market. Technological innovation has reduced the initial costs of renewable energy, including solar power generation, thereby enabling market competition with electricity 


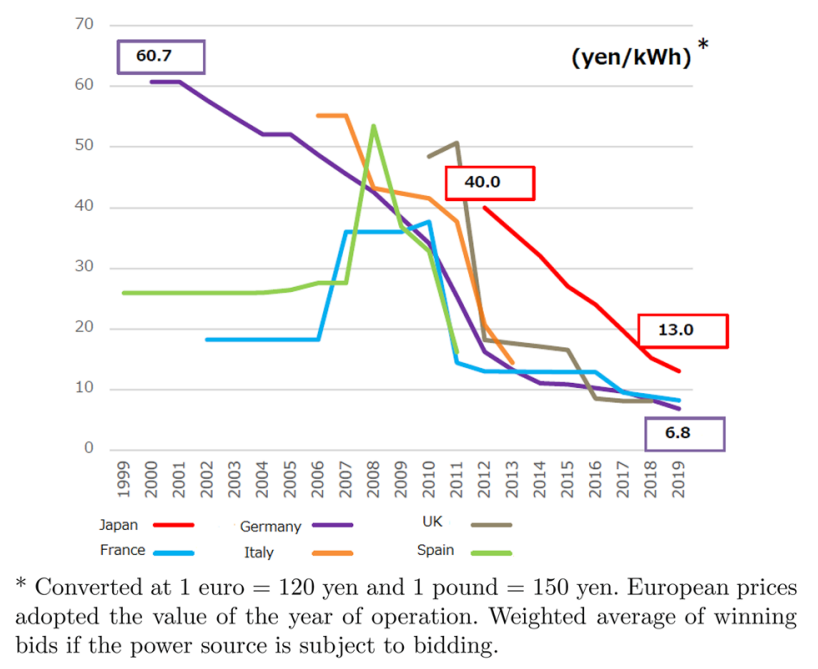

Fig. 1 Change in feed-in-tariff (FIT) purchasing price for solar power in major countries (from METI 2019, translated by Authors)

generated from other sources. To maintain a balance between FIT purchasing prices and market prices, the level of purchasing price is being reduced as the market evolves. In response to deviations from the defined thresholds, purchasing price reductions have accelerated or slowed according to market growth. In 2018, FIT prices in Germany were reduced as the number of solar installations increased by approximately $5.8 \%$ (IEA, 2019).

Conversely, there are some cases where the FIT scheme failed because of improper FIT pricing. In Japan, for example, FIT was launched in 2012 after the 2011 earthquake. Here, FIT payments were shared among electricity consumers and paid in addition to electricity bills. The FIT price was initially set at a high level (40 yen/kWh). However, this setting led to speculative investment. Owing to the high FIT prices, the number of new photovoltaic power generating facilities increased. However, the FIT levy also increased accordingly. Furthermore, unlike Germany's case, the installation cost did not decline, and without FIT assistance, the investment cost remained high. Owing to the high levy, the Japanese government gradually reduced FIT prices. Thus, the purchasing price of electric power by FIT had fallen to 13 yen in 2019. However, Japan's renewable energy ratio remained 16\% in 2017 and has not yet reached the 22-24\% target for 2030 (METI, 2019). If the FIT purchasing price is reduced further, renewable energy investments may stagnate. Subsequently, achieving the renewable energy target will become more difficult.

There are also cases where FIT did not become an investment incentive because of the low price. In Argentina, the FIT system was approved in 2006. However, the purchasing price was set considerably low owing to political opposition. Thus, FIT did not increase renewable energy investment until 2018. ${ }^{1}$ FIT was also introduced

\footnotetext{
1 Argentina's renewable energy ratio has grown rapidly over the past few years. This growth was not due to FIT but Law No.27191 - the law passed by the Argentine Congress in 2015 aimed at promoting renewable energy (KPMG, 2019).
} 
in South Korea from 2002 to 2012, but the renewable energy ratio increased only to $1.5 \%$ during this period (EIA, 2020). Clearly, FIT did not have a significant impact here as it did in the EU. Here, the FIT levy was covered by taxes. Therefore, to avoid the large payments, the Korean government changed its policy from FIT to a Renewable Portfolio Standard. The latter policy obliges power companies to cover a certain ratio of their power generation with renewable energy (Mendonça et al., 2010).

As the latter examples show, although the FIT system was initially a policy to encourage the growth of renewable energy and enable competition with other electric power generation sources, many countries are lowering the purchasing price and abandoning the FIT scheme even before the investment cost decreases. Based on the cases of countries such as Japan and others where FIT systems have failed to function adequately, in this study, we consider how the decrease in FIT purchasing price affects renewable energy investment and what happens to renewable energy investments after the FIT is abolished. By providing evidence on the effects of lowering FIT prices, we contribute to the literature on transition management from FIT to another policy toward achieving a country's renewable energy goals.

We analyze the relationship between the FIT purchasing price and renewable energy investment through a laboratory experiment. This allows us to compare situations with and without the introduction of the FIT scheme. The experiment is based on the standard linear public goods game. Renewable energy investments are modeled as a contribution to the public good. A FIT purchasing price is introduced as a fixed price given to each unit of investment in public goods. We compare two transition patterns of the FIT purchasing price against a baseline situation with a constant zero purchasing price. In one transition pattern, the FIT purchasing price starts at a high level and decreases to zero. In the other transition pattern, the FIT purchasing price starts at a low level and then decreases to zero. Through this experiment, we observe a phenomenon of motivation-crowding-out, often observed in economics and psychology: the contribution of investments in the last phase of zero purchasing price is lower in treatments that experience a non-zero FIT price than in the baseline with no FIT price. This suggests that a decrease in the FIT price with no change in the environment (such as a decrease in the installation costs) can inhibit people's motivation for photovoltaic generation investments.

The rest of this paper is organized as follows. Section 2 undertakes a literature review, and Sect. 3 explains the theoretical settings of a public goods model with a FIT scheme. Further, Sect. 4 introduces our experiment, and Sect. 5 presents the descriptive and empirical results and discusses the observations regarding motivation-crowding-out. Finally, Sect. 6 presents policy implications and concludes this study. 


\section{Related literature}

FIT is a policy like Pigou grants and has been widely recognized in economics. For example, Menanteau et al. (2003) showed that FIT increased the capacity of renewable energy. Lipp (2007) showed that it effectively reduces carbon emissions. According to Rickerson et al. (2007), FIT can also expand the renewable energy market. Using field experiments, Cherry et al. (2012) showed that subsidy policies such as FIT are more likely to be accepted by residents. Their experimental results show that a subsidy policy is supported significantly more than other policies like quantity regulation or taxes. Mitra and Moore (2018) also conducted an experiment that approaches renewable energy as a public good. The authors applied two mechanisms defined by Kotchen and Moore (2008) - the voluntary contribution mechanism (VCM) and the green tariff mechanism (GTM) - to a public goods experiment and compared the provision of public goods. In VCM, the subject directly selects the supply of public goods. In GTM, the subject determines the ratio of consumption of their private goods to the supply of public goods. The results show that the average provision of public goods is higher in VCM.

Based on these studies, we conducted experiments on FIT and voluntary investment in renewable energy. Oberholzer-Gee (2001) and Kotchen and Moore (2007) showed that altruism acts as an incentive for people to participate in programs to conserve the environment. Therefore, it is likely that people are willing to invest in solar energy. We assume that FIT is a monetary reward system that can encourage investment in public goods in addition to voluntary investment. However, as noted in the introduction, we observe behavior in line with motivation crowding out.

Motivation crowding out is a phenomenon in which intrinsic motivation is reduced by external motivation, such as a monetary reward. This phenomenon has been reported in psychology since the 1970s (e.g., Deci, 1971). It has also been analyzed in Economics. For example, using a theoretical model, Frey and Oberholzer-Gee (1997) and Frey and Jegan (2001) showed this phenomenon's relation to the NIMBY problem. Fehr and Gächter (2001) provided evidence that motivation crowding out also occurs in laboratory experiments. They performed laboratory experiments using the Principal-Agent model with and without fines in a contract. They observed that fines reduce the agent's effort level compared to non-fine contracts. Motivation crowding out research has also been conducted using field experiments. For example, Gneezy and Rustichini (2001b) observed that the amount of donated blood decreases when a monetary reward is given to the blood donor. Gneezy and Rustichini (2001a) also reported that when fines are imposed on parents who are late for picking up children at daycare centers, it increased the number of late arrivals.

Recent research has emphasized the need for institutional design that considers motivation crowding out in areas that require non-pecuniary incentives. Bertelli (2006) showed that civil servants could improve their performance more efficiently via an institutional design that considers not only financial compensation, but also motivation crowding out. Studies have shown that the editing of Wikipedia relies on the voluntary cooperation of consumers and is highly associated with motivation crowding out (Gallus, 2017). For more details on motivation 
crowding out and environmental issues, as in this study, see Frey and Stutezer (2006).

This study contributes to the subject by conducting an experiment on renewable energy investment under conditions closer to the current FIT policy and observes motivation crowding out when FIT prices are removed. To the best of our knowledge, this has not yet been discussed in FIT-related literature and is a significant discovery in implementing policies after FIT schemes are phased out.

\section{Theoretical framework: public goods game with FIT}

Assume that there are $N$ players in the public goods game. Each player determines their amount of investment in the public goods within their endowment of 10 points. Let us denote the number of investment points in period $t$ by player $i$ as $X_{i t}$ and the sum of investments by all $N$ members as $\sum_{i} X_{i t}$. Player $i$ 's profit, ignoring the FIT scheme, is the same as the standard linear public goods game and is given as follows:

$$
10-X_{i t}+a \sum_{i} X_{i t}\left(\frac{1}{N}<a<1\right),
$$

where $a$ is the marginal per capita return from the public goods. $\frac{1}{N}<a$ implies that the efficient strategy for the group is for all members to invest all 10 points of their endowment. $a<1$ implies that the dominant strategy for each player is a zero-point investment. Therefore, without any FIT price, the Nash Equilibrium is zero investment for each player. Thus, an inefficient outcome is achieved in the theoretical framework.

We introduce a FIT scheme to this basic public goods game. Let $P_{t}$ be the FIT price for a one-point investment at period $t$. Subsequently, player $i$ 's profit changes as follows:

$$
10-X_{i t}+a \sum_{i} X_{i t}+P_{t} X_{i t}\left(\frac{1}{N}<a<1\right)
$$

In this case, $\frac{1}{N}<a$ still implies that the efficient strategy for the group is for all members to invest their 10 points. However, the dominant strategy changes with the value of $P_{t}$. If $\left(a+P_{t}\right)>1$, player $i$ 's dominant strategy is to invest all 10 points, and if the inequality is reversed, the dominant strategy is not to invest. Therefore, by setting a large $P_{t}$, the government can induce a 10-point investment and achieve an efficient outcome.

As the installation of renewable energy facilities is a long-run investment, modeling it as a repeated investment decision may need some explanation. One possible interpretation for this setting is as follows. The players are the leaders of the adjacent community, and the installation of solar panels creates positive externalities for all communities. In each period, the players decide the number of solar panels to install on one of the potential installation sites from the budget. Thus, in each period, they are making investment decisions for different potential sites. To keep the game as simple as possible, we assume that the positive externality $\left(a \sum_{i} X_{i t}\right)$ and the income from FIT $\left(P_{t} X_{i t}\right)$ in the Eq. (1) also include the present value of future positive externality/income. 
Table 1 Summary of the treatments

\begin{tabular}{|c|c|c|c|c|}
\hline \multirow[t]{2}{*}{ Treatment } & \multirow{2}{*}{$\begin{array}{l}\text { Number of } \\
\text { subjects }\end{array}$} & \multicolumn{3}{|c|}{ FIT price } \\
\hline & & Block 1 & Block 2 & Block 3 \\
\hline HLN & 48 & 0.8 & 0.2 & 0 \\
\hline LLN & 40 & 0.2 & 0.2 & 0 \\
\hline NNN & 44 & 0 & 0 & 0 \\
\hline
\end{tabular}

\section{Experiment design}

The experiment was conducted in December 2019 at Ritsumeikan University's experimental laboratory CHOCOLA in Japan. Nine sessions were conducted, each comprising either 12 or 16 subjects. In total, 132 subjects participated in the experiment, and approximately $80 \%$ were undergraduate students. They were recruited through the university's webpage.

\subsection{Treatment and parameters}

In the experiment, subjects played the public goods game with FIT for 21 periods in three blocks of seven periods each. Subjects were told that a FIT price would be announced at the beginning of each Block and that the same FIT price would be applied throughout that Block. Furthermore, we applied partner matching within each Block and stranger matching among Blocks. Thus, subjects were randomly re-matched into a different group at the beginning of each Block and played in the same group for seven periods.

The game's parameters were as follows. The game was played by four people with an endowment of 10 and a marginal per capita return $a$ of 0.6. The FIT price $P_{t}$ was the main treatment variable, and its value differed between treatments and Blocks. Thus, the payoff for subject $i$ at a strategy profile $X_{t}$ in period $t$ is as follows:

$$
10-X_{i t}+0.6 \times \sum_{i} X_{i t}+P_{t} X_{i t}
$$

Table 1 shows the values of the FIT prices in each Block in each treatment. To examine the effects of decreasing FIT prices on people's investments toward renewable energy projects, we had three treatments that differed in the change in the FIT prices. HLN treatment resembles a situation where the government starts enthusiastically with a high FIT price ( $\mathrm{H}$ for high) but gradually lowers it (L for low) and finally abolishes it ( $\mathrm{N}$ for no policy). LLN treatment resembles a situation where the government introduces a mild FIT policy and finally abolishes it. NNN treatment resembles a situation where the government has no FIT policy. Comparing the behavior of the subjects in Block 3, where no policy is used in all three treatments, helps determine how the introduction of the FIT policy and its abolishment affect the behavior of individuals in the long run.

The theoretical predictions for the different FIT prices used in the experiment are as follows. We used three values for FIT prices: $0.8,0.2$, and 0 . When $P=0.8$, the dominant strategy is to contribute everything. This is because, for every contribution, 
individuals gain 0.6 as a marginal return from the public good and a subsidy of 0.8 , which together is larger than the cost of contribution 1 . When $P=0.2$ and $P=0$, the dominant strategy is to not contribute. Thus, if all players maximize their own payoffs, they would contribute everything in Block 1 of HLN treatment and not contribute anything in all other blocks of all three treatments.

\subsection{Procedures}

As the subjects arrived at the laboratory, they were randomly seated at a computer terminal. These terminals were partitioned so that the subjects could not see the monitors of other participants. They received an oral explanation of the consent form and were given sufficient time to review the content before signing the form. The instructions were read aloud by the experimenter. Subsequently, the subjects took a quiz to check their understanding of the rules of the game. The quiz was checked individually by the experiment's staff, and the experimental program began only after all subjects answered all questions correctly.

Notably, the instructions and programs explained the game in the frame of investments for a solar energy project. The marginal per capita return was explained as the positive externality of clean energy created through the solar energy project. The FIT price was explained as the government subsidy to the investors for undertaking solar energy projects. This frame may lower the generalizability of our findings. However, it adds external validity for analyzing the main target of this research.

Each block proceeded as follows. At the beginning of each block, the experimenter announced the FIT price of the block. If the FIT price was different from that of the previous block, a payoff matrix was distributed that informed subjects of their own payoffs, given the combination of their investment and the sum of investments by the other three members. The subjects were given one minute to check the payoff matrix. Subsequently, the computer program started, where they played the game for seven periods. ${ }^{2}$

In each period, the subjects were reminded of the FIT price and asked to enter the amount they wanted to invest. After all the subjects had decided, the feedback information screen appeared, where they were informed about the following: their own investment, the sum of investments of the group, the points they retained, the points earned from the sum of investments and the subsidy, and the total points they earned in that period. ${ }^{3}$

After all three blocks were completed, the subjects answered the questionnaire. ${ }^{4}$ This questionnaire included questions on the following: their major, trust level (Yamagishi \& Yamagishi, 1994), risk attitude (Dohmen et al., 2011), social value orientation (SVO) using a slider measure (Murphy et al., 2011), subjective

\footnotetext{
2 The experiment was programmed and conducted using zTree (Fischbacher, 2007).

3 Here, the subjects were not informed about the amount of investments or the points earned by the other group members (see Fiala \& Suetens, 2017 for the results related to individual and aggregate feedback information in public goods games).

4 Owing to a programming error, we could not obtain most of the questionnaire data for the 16 subjects in the first session.
} 
Table 2 Average investments

\begin{tabular}{llll}
\hline & Block 1 & Block 2 & Block 3 \\
\hline HLN & 7.979 & 3.693 & 2.485 \\
LLN & 3.614 & 3.404 & 2.043 \\
NNN & 2.565 & 3.000 & 3.286 \\
Kruskal & 0.000 & 0.113 & 0.000 \\
\hline
\end{tabular}

evaluation of the understanding of the experiment, their attitude toward environmental issues (4 point increasing scale), and whether they were conscious about the fact that their decisions were about a solar energy investment.

For more details about each element and the summary statistics, see Table 5 in the Appendix. This table shows that there are no statistically significant differences between the treatments for all the questions, suggesting that the subjects were wellrandomized across the treatments. ${ }^{5}$

At the end of the experiment, the subjects received payments in cash. They were paid for the sum of points they had earned in three periods, each of which was randomly chosen from each block. The sum of points was exchanged at a rate of 1 point $=30$ Yen and was paid with a participation fee of 500 Yen. In total, the average payment was 1,963 Yen or approximately $\$ 18$ at the time of the experiment. The experiment lasted for approximately 1.25 hours. This average payment is about 1.8 times the prefecture's minimum wage.

\section{Results}

\subsection{Descriptive analysis}

Average investments by treatments and blocks are shown in Table 2. In the Kruskal-Wallis rank sum test, individual data in each period were used as the unit of observation. The results imply that high purchasing prices induce high average investment. In Block 1, for example, the average investment is approximately 8 points in HLN (FIT price is 0.8 ) and 2.5 points in NNN (FIT price is 0 ). However, comparing the average investments in Block 3, in which the FIT price is equal to 0 for all treatments, NNN's investment is larger than that of the other two treatments. The difference between LLN and NNN in Block 3 is significant at the $5 \%$ level using the t-test.

Figure 2 shows the average investment in each round. In Block 1, as mentioned above, the level of investment is large for HLN. This also shows that the strategy is gradually approaching the equilibrium strategy of investing all 10 points.

\footnotetext{
5 The question on the solar frame, which checked whether the subjects were conscious about the solar energy investment, is significant at the $10 \%$ level. However, the result of pair-wise comparison using Wilcoxon-rank sum test is not significant at the $10 \%$ level for any of the pair-wise comparisons.
} 


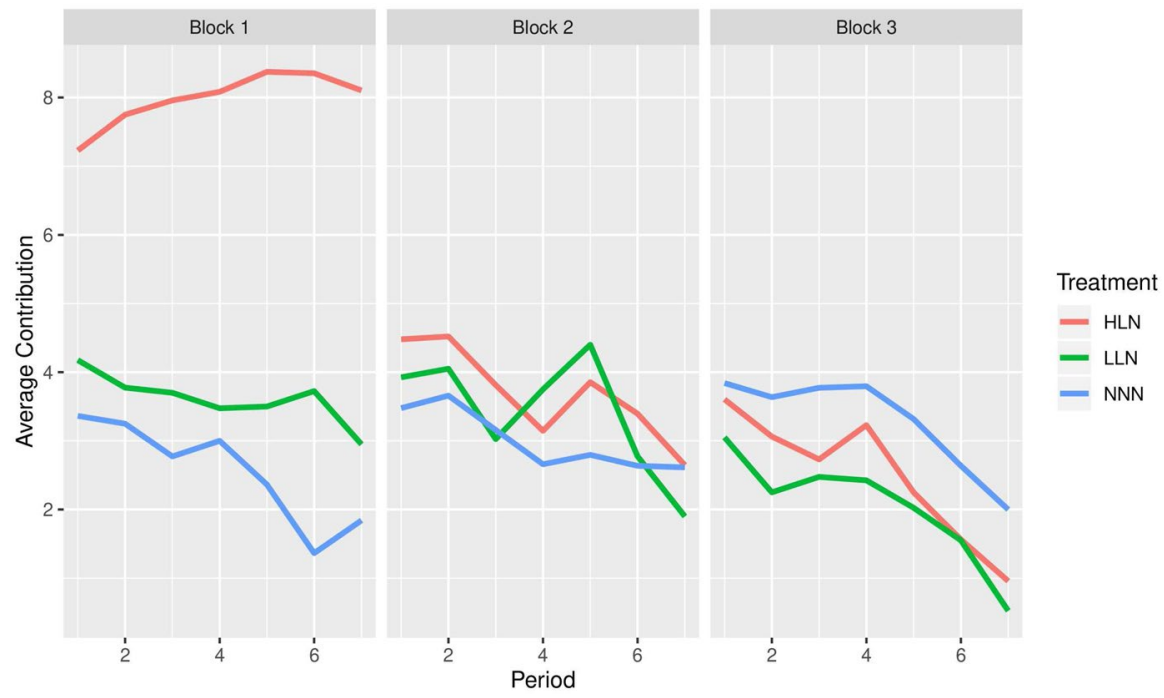

Fig. 2 Transition of average investments

Although the equilibrium strategy for both prices, 0.2 and 0 , is zero points, LLN has a higher investment over time than NNN. In Blocks 2 and 3, NNN's investment increases slightly, indicating that spontaneous motivation for investment has been created over time. In Block 3, NNN has the highest average investment in all rounds, although prices are 0 for all treatments.

Figure 3 represents the percentage of subjects who invested 0 (free riding) in each round. In Block 1, the free rider ratio is considerably low in HLN. This is reasonable given that the dominant strategy is to invest their entire endowment in this treatment. The free rider ratio is higher in the other two treatments, exceeding $50 \%$ in NNN. However, in Block 3, the free rider ratio for NNN is lower than in the other two treatments. Furthermore, the ratio decreases in NNN as the blocks proceed. These results suggest that the higher average investments in NNN in block 3 are not induced by a few unconditional cooperators fully contributing while the others are completely freeriding on them. Rather, it suggests that many subjects are contributing to a certain extent.

These results show that although the treatments were randomly assigned, one may suspect that subjects with cooperative attributes were accidentally concentrated in NNN compared to the other two treatments. However, as stated in the experiment design section and as shown in Table 5, none of the measures are statistically significantly different across the three treatments at the 5\% level. This suggests that there is no distributional bias in subject attributes, and the observed results of the experiment are induced by the change in the FIT prices.

Finally, to check whether the introduction of FIT helped increase the aggregate level of contribution, we compare the cumulative contributions across the three treatments (see Table 3). We calculate the sum of contributions made in all 21 


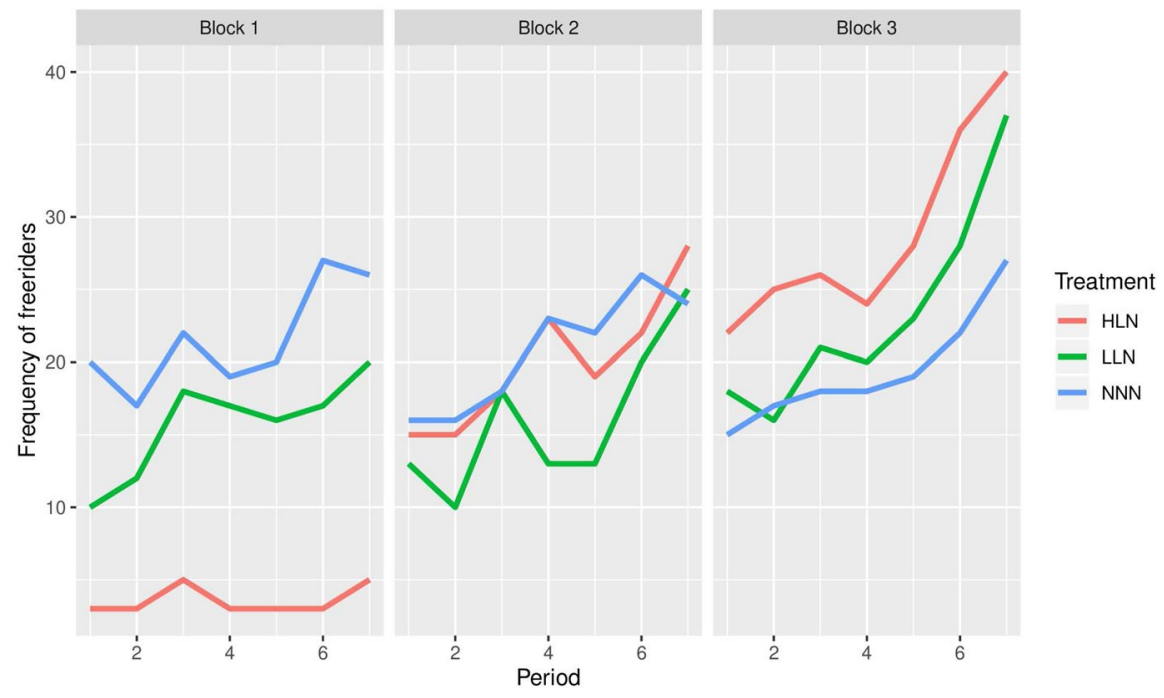

Fig. 3 Frequency of complete freeriders

Table 3 Accumulative contributions

\begin{tabular}{llll}
\hline Treatment & HLN & LLN & NNN \\
\hline Accumulative contributions & 99.104 & 63.425 & 61.955 \\
\hline
\end{tabular}

periods for each individual and use this as a unit of observation. The $p$ value of the Kruskal-Wallis rank sum test is less than 0.001 . Thus, we reject the null hypothesis that all three treatments have equal distribution of the cumulative contributions. We also conduct a pair-wise Wilcoxon-rank sum test to see which of the three treatments have significant differences. Additionally, we use Holm's p-adjustment method. We find that HLN treatment is significantly different from the other two treatments at the $1 \%$ level. Conversely, there are no statistically significant differences between LLN and NNN. This suggests that it is preferable to have stronger stimuli while introducing the FIT scheme, as the low FIT purchasing price may not raise the contributions of individuals sufficiently and could instead have a detrimental effect on contributions when abolished.

Next, we analyze the individual investment behaviors in more detail using regression analysis.

\subsection{Regression results}

Using the panel dataset, we estimate generalized-least-squares (GLS) regressions using a random effect model (3) to explain individual contributions. The dataset contains observations from 115 subjects with their attribute variables such as SVO _Angle and Trust. 
Table 4 Regression results

\begin{tabular}{|c|c|c|c|c|}
\hline Variables & All & Block 1 & Block 2 & Block 3 \\
\hline BuyPrice & $7.255 * * *(23.149)$ & - & - & - \\
\hline HLN & $\begin{array}{c}-1.038^{* *} *(- \\
2.150)\end{array}$ & $5.130 * * *(9.063)$ & $0.526(0.872)$ & $\begin{array}{l}-1.514 * *(- \\
2.526)\end{array}$ \\
\hline LLN & $-0.615(-1.356)$ & $1.389 * *(2.561)$ & $0.676(1.169)$ & $-1.008 *(-1.755)$ \\
\hline SVO_Angle & $0.023^{*}(1.937)$ & $0.043 * * *(2.968)$ & $0.023(1.486)$ & $0.004(0.270)$ \\
\hline Trust & $0.073(0.288)$ & $-0.063(-0.209)$ & $0.107(0.330)$ & $0.175(0.544)$ \\
\hline Eco & $-0.167(-0.744)$ & $-0.171(-0.634)$ & $-0.283(-0.986)$ & $-0.047(-0.164)$ \\
\hline Solar & $\begin{array}{l}-0.353 * * *(- \\
2.697)\end{array}$ & $\begin{array}{c}-0.357 * *(- \\
2.272)\end{array}$ & $\begin{array}{c}-0.326^{*}(- \\
1.944)\end{array}$ & $\begin{array}{l}-0.376^{* *}(- \\
2.260)\end{array}$ \\
\hline Risk_Attitude & $0.389 * * *(5.677)$ & $0.433 * * *(5.262)$ & $0.347 * * *(3.955)$ & $0.387 * * *(4.440)$ \\
\hline Understanding & $-0.105(-0.380)$ & $-0.073(-0.219)$ & $-0.133(-0.375)$ & $-0.110(-0.312)$ \\
\hline Constant & $3.020(1.444)$ & $2.209(0.879)$ & $3.547(1.325)$ & $3.305(1.242)$ \\
\hline Observations & 2,415 & 805 & 805 & 805 \\
\hline Number of subjects & 115 & 115 & 115 & 115 \\
\hline$R^{2}$ within & 0.189 & 0 & 0 & 0 \\
\hline$R^{2}$ between & 0.367 & 0.564 & 0.217 & 0.247 \\
\hline$R^{2}$ overall & 0.255 & 0.400 & 0.113 & 0.151 \\
\hline
\end{tabular}

$z$-Statistics in parentheses

$* * * p<0.01, * * p<0.05$, and $* p<0.1$

$$
\begin{aligned}
C_{i t}= & \alpha+\beta_{1} \text { BuyPrice }_{i t}+\beta_{2} \mathrm{HLN}_{i}+\beta_{3} \mathrm{LLN}_{i}+\beta_{4} \text { SVO_Angle }_{i}+\beta_{5} \text { Trust }_{i} \\
& +\beta_{6} \mathrm{Eco}_{i}+\beta_{7} \text { Solar }_{i}+\beta_{8} \text { Risk Attitude }_{i}+\beta_{9} \text { Understanding }_{i}+\gamma_{i}+\epsilon_{i t}
\end{aligned}
$$

where

$i$ indexes individuals and $t$ indexes rounds; $C_{i t}$ : contribution by individual $i$ at round $t ; \alpha$ : constant; BuyPrice $i t$ : purchasing price under the FIT scheme; HLN $_{i}$ : treatment effect variable for treatment $1 ; \mathrm{LLN}_{i}$ : treatment effect variable for treatment 2; $\mathrm{SVO} \_A n g l e_{i}$ : social value orientation of individual $i$; Trust ${ }_{i}$ : trust level of individual $i$; $\mathrm{Eco}_{i}$ : eco-consciousness of individual $i$; Solar ${ }_{i}$ : consciousness to invest in solar power generation (1: strongly yes to 6: no); Risk_Attitude ${ }_{i}$ : risk-take attitude index of individual $i$; Understanding ${ }_{i}$ : understanding level of the experiment; $\gamma_{i}$ : individual fixed effects; and $\epsilon_{i t}$ : idiosyncratic error term.

Table 4 presents the corresponding regression estimates of four different observation groups: ALL (all observations), Block 1, Block 2, and Block 3. As expected, in the ALL case, the purchasing price under the FIT scheme has a significantly positive effect on the contribution ( +0.726 per 0.1 price increase). This variable is not available for the cases of Block 1, Block 2, and Block 3 because the purchasing price is stable within each Block. The effects of HLN and LLN treatments are significantly positive in Block $1(+5.130$ and +1.389 , respectively) and significantly negative in Block $3(-1.514$ and -1.008 , respectively) compared to NNN treatment effects. In Block 2, there are no significant treatment effects. 
The relationship between individual characteristics and investment behavior is as follows. First, the consciousness to invest in solar power generation has significantly negative effects on the contribution $(-0.326 \sim-0.376)$. Furthermore, risk-taking attitudes cause significantly positive effects on the contribution $(+0.347 \sim+0.433)$. SVO_Angle has a significantly positive effect $(+0.043)$ in Block 1, while the effects disappear in Blocks 2 and 3. Finally, neither trust nor eco-consciousness has any significant effects on the contribution to solar generation investment.

\subsection{Discussion: motivation crowding out theory}

The analyses in Sects. 5.1 and 5.2 reveal puzzling results from Blocks 2 and 3. In Block 2, although the price was higher in HLN and LLN than in NNN, no treatment difference was observed. Furthermore, in Block 3, HLN and LLN had negative effects on contributions, although the three treatments had the same FIT price of zero. ${ }^{6}$ In this subsection, we explain these observations using motivation crowding out theory. $^{7}$

Motivation crowding out is a phenomenon where external motivations, such as money, reduce an individual's intrinsic motivation to cooperate. The observations in Block 3 are in line with this explanation. NNN is the treatment where the subjects never received an external motivation. However, in the other two treatments, subjects received an external motivation in all the previous rounds. Thus, the FIT scheme might have reduced their intrinsic motivations to invest.

To analyze this in more detail, we modify the theoretical model described in Sect. 3 and present a model that includes a possibility for the motivation crowding out to occur. This model allows us to explain the experimental results as an equilibrium outcome.

\footnotetext{
${ }^{6}$ One may be interested in the relationship between subject type and the tendency to decrease their contribution with a decrease in the FIT price. We did not find any clear tendency between the subjects' SVO type and the tendency to crowd out their motivation. However, we found that in HLN and LLN, people who were more conscious of the solar energy frame decreased their contribution more as the block proceeded than those who were not conscious of it. This tendency was not observed in NNN, where the FIT price did not change over rounds.

7 Another possible explanation for the decrease in average contributions over blocks in treatments with the decreasing FIT price is the change in beliefs about other group members' contributions. Previous literature has shown a positive correlation between people's beliefs about other members' contribution level and their own contribution in the public goods game experiments (c.f., Croson, 2007; Neugebauer et al., 2009; Fischbacher \& Gächter, 2010). This experimental evidence was in line with the hypothesis that people are partial conditional cooperators (c.f., Fischbacher et al., 2001; Kocher et al., 2008): they reciprocate partially to others' contributions. As the marginal benefit of contribution decreases as the FIT price decreases, subjects in this experiment likely lowered their expectation of the contributions by others with the decrease in the FIT price. This, together with the findings from the literature, would suggest lower FIT prices to decrease the average contribution. However, even with the combination of belief and partial conditional cooperation, it is difficult to explain the difference in contribution level in Block 3, where the FIT price was set to zero in all three treatments. To explain this finding, we need further assumptions. An example would be a FIT price history-dependent-belief that expects others to contribute less even at the same FIT price when the FIT price in the previous block was higher than that of the current block.
} 
The theoretical structure is based on the study of Frey and Oberholzer-Gee (1997). We assume that players will spontaneously invest in public goods owing to not only external financial gains but also intrinsic factors. We denote player $i$ 's psychological gains from investing $X_{i t}$ in the public goods in period $t$ as $F\left(X_{i t}\right)$. We assume that $F\left(X_{t}\right) \geq 0, \mathrm{~d} F\left(X_{t}\right) / \mathrm{d} X_{t} \equiv F_{X}\left(X_{t}\right)>0$ and $\mathrm{d} F_{X}\left(X_{t}\right) / \mathrm{d} X_{t}<0$ for all $X_{t}$. In addition, we assume that motivation crowds out. Thus, this intrinsic gain is impaired by the generation of external rewards. The cost is represented by $C\left(X_{i t}, h_{t}\right)>0$. We assume that $\mathrm{d} C\left(X_{t}, h_{t}\right) / \mathrm{d} X_{t} \equiv M C\left(X_{t}, h_{t}\right)>0$ and $\mathrm{d} M C\left(X_{t}, h_{t}\right) / \mathrm{d} X_{t}>0 . h_{t}$ is the history of the FIT price $\left\{P_{k}\right\}_{k=1,2, . .,}$. Let $h_{t}^{0}=(0,0, . ., 0)$-FIT prices are zero until period $t$. The following assumption indicates that motivation crowding out occurs when the FIT price takes a positive value at some point in the past.

Assumption $1 M C\left(X_{i t} ; h_{t}\right) \geq M C\left(X_{i t} ; h_{t}^{0}\right)$ for all $X_{i t}>0$ and all history $h_{t}$.

The intrinsic gain is expressed by these two terms:

$$
F\left(X_{i t}\right)-C\left(X_{i t}, h_{t}\right)
$$

As each player's total gain is the sum of the external and intrinsic gain, it can be expressed as follows:

$$
10-X_{i t}+a \times \sum_{i} X_{i t}+P_{t} X_{i t}+F\left(X_{i t}\right)-C\left(X_{i t}, h_{t}\right)
$$

Each player decides $X_{i t}$ to maximize this gain. Given the price history $h_{t}$, the optimal investment amount does not depend on $t$ because the player optimizes the gain in each period. If the optimal investment $X_{i t}^{*}$ is the interior solution $\left(0<X_{i t}^{*}<10\right)$, the first order condition implies the following :

$$
\left(a+P_{t}\right)-1+F_{X}\left(X_{i t}^{*}\right)-M C\left(X_{i t}^{*}, h_{t}\right)=0
$$

$\mathrm{d} F_{X}\left(X_{t}\right) / \mathrm{d} X_{t}<0 \quad$ and $\mathrm{d} M C\left(X_{t}, h_{t}\right) / \mathrm{d} X_{t}>0 \quad$ imply that $\left(a+P_{t}\right)-1+F_{X}\left(X_{i t}^{*}\right)-M C\left(X_{i t}^{*}, h_{t}\right)$ is decreasing in $X_{t}$. This equation determines the equilibrium investment $X_{i t}^{*}$. Therefore, the investment is decided by the external and intrinsic motivations in the model.

We assume that motivation crowding out, like Assumption 1, occurs in the experiment. Let $X_{i t}^{M}$ be player $i$ 's optimal investment in period $t$ given $h_{t}^{0}$. Subsequently, we can imply the following theorem:

Theorem 1 If $P_{k}>0$ for some $k \leq t, X_{i t}^{M} \geq X_{i t}^{*}$ when $P_{t}=0$.

Proof By the first order condition,

$$
\left(a+P_{t}\right)-1+F_{X}\left(X_{i t}^{*}\right)-M C\left(X_{i t}^{*}, h_{t}\right)=0
$$

By the definition of $X_{i t}^{M}$,

$$
\left(a+P_{t}\right)-1+F_{X}\left(X_{i t}^{M}\right)-M C\left(X_{i t}^{M}, h_{t}^{0}\right)=0
$$


Fig. 4 Optimal investment in motivation crowding out

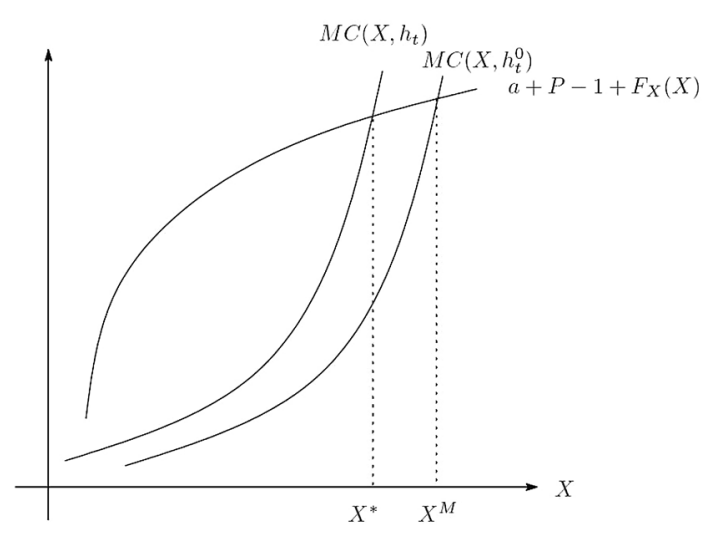

From Assumption 1 ,

$$
\operatorname{MC}\left(X_{i t} ; h_{t}\right) \geq \operatorname{MC}\left(X_{i t} ; h_{t}^{0}\right)
$$

for all $X_{t}$.

As $\left(a+P_{t}\right)-1+F_{X}\left(X_{i t}^{*}\right)-M C\left(X_{i t}^{*}, h_{t}\right)$ is decreasing in $X_{t}, X_{i t}^{M}$ must be greater than or equal to $X_{i t}^{*}$ (see Fig. 4$)$.

This theorem shows that the introduction of FIT reduces the amount of investment when the price reaches zero. Introducing FIT and encouraging investment will undermine intrinsic motivation, and when the FIT is abolished, the investment will be less than before the FIT was introduced.

\section{Policy implications and conclusion}

Using a laboratory experiment, this study investigates behavioral changes in solar photovoltaic generation investment during the FIT scheme's transition. These investments can be regarded as both private goods investment and public goods contribution. This is because they not only increase profits from FIT but also cause positive externalities such as reduction in air pollution and climate change mitigation in cooperation with other contributors. We consider the recent FIT trend in several countries where the purchasing price has been decreasing annually.

First, in line with the extensive experimental literature on the public goods game (e.g., Ledyard, 1995; Croson, 2010), we find that the average contributions in all periods are positive even in the case where the dominant strategy is zero contribution. This suggests that our solar energy investment frame has no substantial effect on subjects' behavior. 
Second, the contributions at a zero FIT price, under the price decreasing condition, are less than those without a FIT scheme from the start. This is not caused by the differences in individual characteristics such as social value orientation across three treatments. Thus, the motivation to invest voluntarily in public goods may be hindered by experiencing the subsidy under FIT. That is, the motivation to mitigate climate change may be crowded out under the FIT scheme's transition.

Third, our study indicates that the LLN treatment not only caused reduced cumulative contributions than those in the HLN treatment but also induced motivation crowding out compared to the NNN treatment. This suggests that governments must avoid introducing ineffective FIT schemes like the LLN case, where a purchasing price starts at a considerably low level and eventually reaches zero.

In summary, our experimental results show the negative effects of lowering FIT prices. However, the FIT scheme was originally designed so that the purchasing price gradually declines and is finally terminated in 10-20 years as the initial installation costs decrease owing to the economies of scale and technological improvement. Thus, although voluntary contributions played a role, if governments had not introduced a strong stimulating policy such as FIT, renewable energy might not have proliferated as rapidly.

Finally, considering the possibility that motivation crowding out has already occurred during the FIT phaseout process, it is important to introduce a new policy instrument without a break to stimulate renewable energy investments. Feed-in premium (FIP) schemes are expected to succeed FIT. They have already been introduced in some European countries and are at the preparatory stage in Japan. The FIP scheme is designed in conjunction with electric power transaction markets. The premium for the purchasing price will be added to the time-variant market price and will reflect power generation marginal costs. The FIP seems to be more stable and sustainable than FIT as the avoidable power generation costs due to renewable energy will exist for several years, although it may fluctuate and is lower than FIT prices. Further research is essential for designing effective and efficient FIP schemes and avoiding motivation crowding out, as observed in this study.

\section{A Appendix: additional figures and tables}




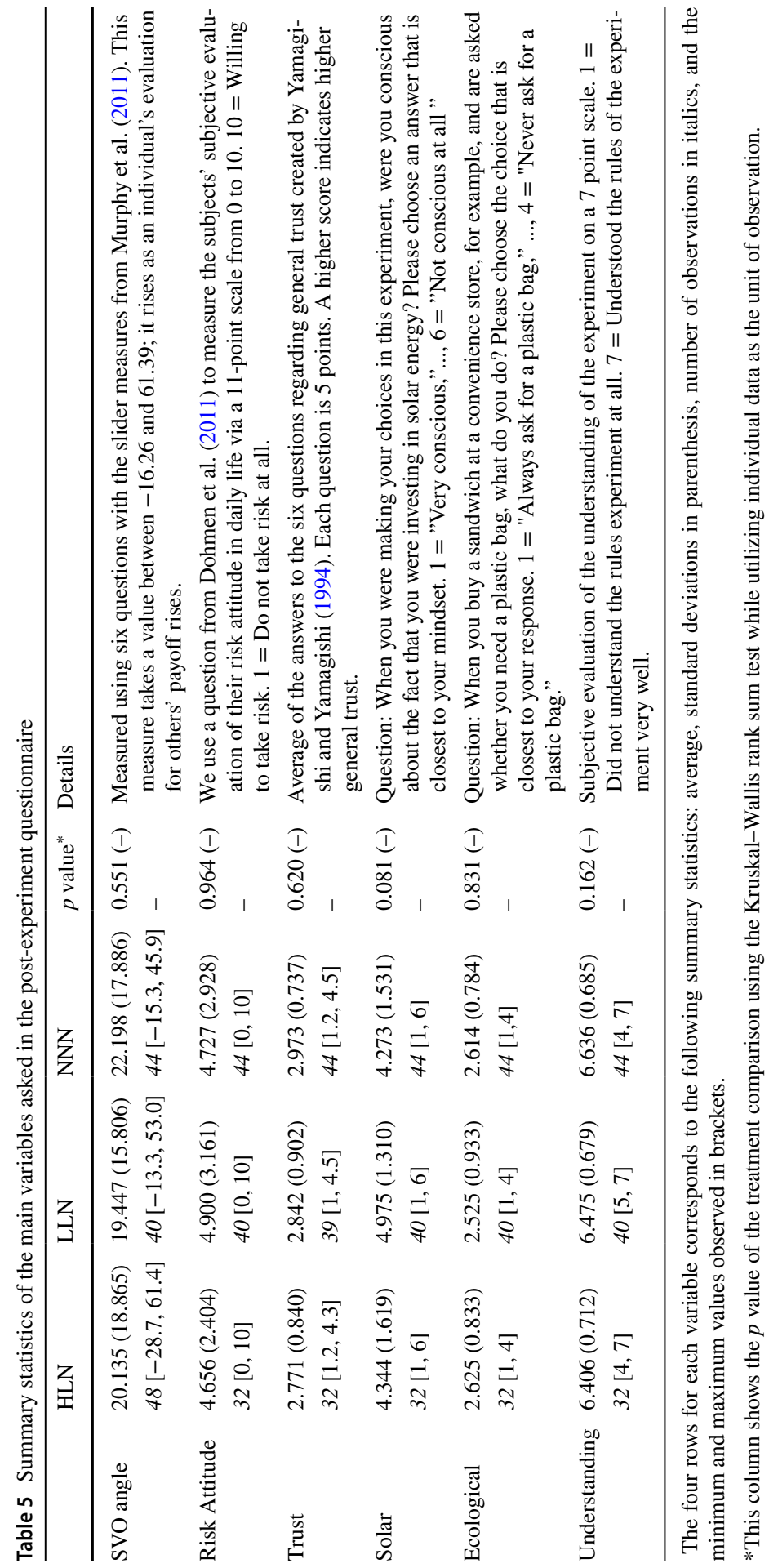


Acknowledgements This experiment was approved by the Ritsumeikan University Ethics Review Committee for Research Involving Human Participants. We are grateful for helpful comments from Takanori Ida at the 2020 Japanese Economic Association Autumn Meeting and to the participants of the 2021 International Workshop for Lab and Field Experiments. This research was supported by the Social System Research Institute, Ritsumeikan University, and JSPS KAKENHI Grant number 15k00645.

\section{Declarations}

Conflict of interest The authors declare that they have no conflict of interest.

Open Access This article is licensed under a Creative Commons Attribution 4.0 International License, which permits use, sharing, adaptation, distribution and reproduction in any medium or format, as long as you give appropriate credit to the original author(s) and the source, provide a link to the Creative Commons licence, and indicate if changes were made. The images or other third party material in this article are included in the article's Creative Commons licence, unless indicated otherwise in a credit line to the material. If material is not included in the article's Creative Commons licence and your intended use is not permitted by statutory regulation or exceeds the permitted use, you will need to obtain permission directly from the copyright holder. To view a copy of this licence, visit http://creativecommons.org/licen ses/by/4.0/.

\section{References}

Bertelli, A. M. (2006). Motivation crowding and the federal civil servant: Evidence from the US internal revenue service. International Public Management Journal, 9(1), 3-23.

Cherry, T. L., Kallbekken, S., \& Kroll, S. (2012). The acceptability of efficiency-enhancing environmental taxes, subsidies and regulation: An experimental investigation. Enviromental Science and Policy, $16,90-96$.

Croson, R. (2007). Theories of commitment, altruism and reciprocity: Evidence from linear public goods games. Economic Inquiry, 45(2), 199-216. https://doi.org/10.1111/j.1465-7295.2006.00006.X

Croson, R. T. A. (2010). Public goods experiments. In S. N. Durlauf \& L. E. Blume (Eds.), Behavioural and experimental economics. Macmillan Publishers.

Deci, E. L. (1971). Effects of externally mediated rewards on intrinsic motivation. Journal of Personality and Social Psychology, 18(1), 105-115.

Dohmen, T., Falk, A., Huffman, D., Sunde, U., Schupp, J., \& Wagner, G. G. (2011). Individual risk attitudes: Measurement, determinants, and behavioral consequences. Journal of the European Economic Association, 9(3), 522-550.

EIA. (2020). EIA international data. Data, US Energy Information Administration. Available online: https://www.eia.gov/international/data/world. Last accessed on 29 Apr 2021.

Fehr, E., \& Gächter, S. (2001). Do incentive contracts crowd out voluntary cooperation? CEPR Discussion Paper (3017)

Fiala, L., \& Suetens, S. (2017). Transparency and cooperation in repeated dilemma games: A meta study. Experimental Economics, 20, 755-771.

Fischbacher, U. (2007). z-tree. Zurich toolbox for readymade economic experiments. Experimental Economics, 10(2), 171-178.

Fischbacher, U., \& Gächter, S. (2010). Social preferences, beliefs, and the dynamics of free riding in public goods experiments. The American Economic Review, 100(1), 541-556.

Fischbacher, U., Gächter, S., \& Fehr, E. (2001). Are people conditionally cooperative? Evidence from a public goods experiment. Economics Letters, 71(3), 397-404. https://doi.org/10.1016/S01651765(01)00394-9

Frey, B. S., \& Jegan, R. (2001). Motivation crowding theory: A survey of empirical evidence. Journal of Economic Surveys, 15(5), 589-611.

Frey, B. S., \& Oberholzer-Gee, F. (1997). The cost of price incentives: An empirical analysis of motivation crowding-out. The American Economic Review, 87(4), 746-755. 
Frey, B.S., \& Stutezer, A. (2006). Environmental morale and motivation. Institute for Empirical Research in Economics University of Zurich Working Paper Series (288)

Gallus, J. (2017). Fostering public good contributions with symbolic awards: A large-scale natural field experiment at Wikipedia. Management Science, 63(12), 1-17.

Gneezy, U., \& Rustichini, A. (2001a). A fine is a price. Journal of Legal Studies, 29, 1-18.

Gneezy, U., \& Rustichini, A. (2001b). Pay enough or don't pay at all. Quarterly Journal of Economics, 115(3), 791-810.

IEA. (2019). Trend in photovoltaic applications 2019. IEA report, International Energy Agency. https:// ieapvps.org/trends_reports/2019-edition/. Accessed 30 Mar 2020.

Kocher, M. G., Cherry, T., Kroll, S., Netzer, R. J., \& Sutter, M. (2008). Conditional cooperation on three continents. Economics Letters, 101(3), 175-178. https://doi.org/10.1016/j.econlet.2008.07.015

Kotchen, M. J., \& Moore, M. R. (2007). Private provision of environmental public goods: Household participation in green-electricity programs. Journal of Environmental Economics and Management, 53, 1-16.

Kotchen, M. J., \& Moore, M. R. (2008). Conservation: From voluntary restraint to a voluntary price premium. Enviromental and Resource Economics, 40(2), 195-215.

KPMG. (2019). Development of renewable energy in Argentina. KPMG report, KPMG. https://assets. $\mathrm{kpmg} /$ content/dam/kpmg/ar/pdf/development-renewable-energy-argentina-2019.pdf. Last accessed on 30 Mar 2020.

Ledyard, J. O. (1995). Public goods: A survey of experimental research. In J. H. Kagel \& A. E. Roth (Eds.), Handbook of experimental economics. Princeton University Press.

Lipp, J. (2007). Lessons for effective renewable electricity policy from Denmark, Germany and the United Kingdom. Energy Policy, 35(11), 5481-5495.

Menanteau, P., Finon, D., \& Lamy, M. L. (2003). Prices versus quantities: Choosing policies for promoting the development of renewable energy. Energy Policy, 31(8), 799-812.

Mendonça, M., Jacobs, D., \& Sovacool, B. K. (2010). Powering the green economy: The feed-in tariff handbook. Routledge.

METI. (2019). Current situation of renewable energy in japan and overseas (in Japanese). METI report, Ministry of Economy, Trade and Industry. https://www.meti.go.jp/shingikai/santeii/pdf/046_01_00. pdf. Accessed 30 Mar 2020.

Mitra, A., \& Moore, M. R. (2018). Green electricity markets as mechanisms of public-goods provision: Theory and experimental evidence. Enviromental and Resource Economics, 71, 45-71.

Murphy, R. O., Ackermann, K. A., \& Handgraaf, M. J. J. (2011). Measuring social value orientation. Judgement and Decision Making, 6, 771-781.

Neugebauer, T., Perote, J., Schmidt, U., \& Loos, M. (2009). Selfish-biased conditional cooperation: On the decline of contributions in repeated public goods experiments. Journal of Economic Psychology, 30(1), 52-60. https://doi.org/10.1016/j.joep.2008.04.005

Oberholzer-Gee, F. (2001). Environmental contracts: Comparative approaches to regulatory innovation in the United States and Europe (p. 2001). Kluwer Law International.

Rickerson, W., Sawin, J. L., \& Grace, R. C. (2007). If the shoe FITs: Using feed-in tariffs to meet US renewable electricity targets. Electricity Journal, 20(4), 73-86.

Yamagishi, T., \& Yamagishi, M. (1994). Trust and commitment in the United States and Japan. Motivation and Emotion, 18, 129-166.

Publisher's Note Springer Nature remains neutral with regard to jurisdictional claims in published maps and institutional affiliations. 